\title{
Conformational Search on the Lewis X Structure by Molecular Dynamic: Study of Tri- and Pentasaccharide
}

\author{
N. Khebichat, K. Nekkaz, and S. Ghalem \\ Laboratory of Natural Products and Bio Actives, Department of Chemistry, Faculty of Sciences, Aboubakr Belkaid University, \\ Tlemcen 13000, Algeria \\ Correspondence should be addressed to S. Ghalem, s_ghalem2002@yahoo.fr
}

Received 4 July 2011; Revised 7 October 2011; Accepted 12 October 2011

Academic Editor: Yuriy A. Knirel

Copyright ( $\odot 2012$ N. Khebichat et al. This is an open access article distributed under the Creative Commons Attribution License, which permits unrestricted use, distribution, and reproduction in any medium, provided the original work is properly cited.

Carbohydrates play vital roles in many biological processes, such as recognition, adhesion, and signalling between cells. The Lewis $\mathrm{X}$ determinant is a trisaccharide fragment implicated as a specific differentiation antigen, tumor antigen, and key component of the ligand for the endothelial leukocyte adhesion molecule, so it is necessary or essential to determine and to know their conformational and structural properties. In this work, conformational analysis was performed using molecular dynamics (MD) simulation with the AMBER10 program package in order to study the dynamic behavior of of the Lewis X trisaccharide $(\beta$-D-Gal$(1,4)-[\alpha$-L-Fuc- $(1,3)]-\beta$-D-GlcNAc-OMe) and the Lewis X pentasaccharide $(\beta$-D-Gal- $(1,4)-[\alpha-L-F u c-(1,3)]-\beta$-D-GlcNAc- $(1,3)$ $\beta$-D-Gal-(1,4)- $\beta$-D-Glu-OMe) in explicit water model at $300 \mathrm{~K}$ for $10 \mathrm{~ns}$ using the GLYCAM 06 force field.

\section{Introduction}

In nature, carbohydrates form an important family of biomolecules, as simple or complex carbohydrates, either alone or covalently linked to proteins or lipids [1]. They play vital roles in many biological processes, such as recognition, adhesion, and communication between cells. Carbohydrates that are covalently linked to a nonsugar moiety (proteins, peptides, or lipids) are the most prominent cell-surfaceexposed structures. The highly diverse structural variability of carbohydrates makes them good candidates for cell receptors and recognition molecules [2].

Determination of the three-dimensional structure of oligosaccharides and understanding the molecular basis of their recognition by receptors represent the main challenges of structural glycobiology. Elucidation of the threedimensional structures and the dynamical properties of oligosaccharides is a prerequisite for a better understanding of the biochemistry of recognition processes and for the rational design of carbohydrate-derived drugs [1].

The human histo-blood group $\mathrm{ABH}(\mathrm{O})$ systems were the first major human alloantigens to be identified. The carbohydrate nature of the $\mathrm{A}, \mathrm{B}, \mathrm{H}$, and Lewis antigens was established in 1950s [3, 4]. Figure 1 shows a schematic representation of current histo-blood group antigens although additional rare types also exist [5]. The oligosaccharidic epitope of $\mathrm{ABH}(\mathrm{O})$ and Lewis histo-blood groups have been the subject of many structural investigations. The energy maps of all of the disaccharides have been established by molecular mechanics methods $[6,7]$.

The determination of conformational preferences of oligosaccharides is best approached by describing their preferred conformations on potential energy surfaces as a function of the glycosidic linkage $\varphi, \psi$ torsional angles. In the early days of conformational analysis of oligosaccharides, the calculations of either rigid or, later, relaxed conformational maps predominated. Today, complex simulation techniques such as molecular dynamics are increasingly being used. Several examples can be found in the literature of "state-ofthe-art" conformational search strategies in order to simplify the complexity of the multiple-minima problem [8].

In this work, we carried out extensive, explicit solvent MD simulation studies for tri- and pentasaccharide Lewis $\mathrm{X}$ for $10 \mathrm{~ns}$. Each monosaccharide unit in the Lewis $\mathrm{X}$ molecules adopts the typical ${ }^{4} \mathrm{C}_{1}$ chair conformation, with no significant deviation from the classical pyranose ring shape. 
$\mathrm{ABH}(\mathrm{O})$ antigens

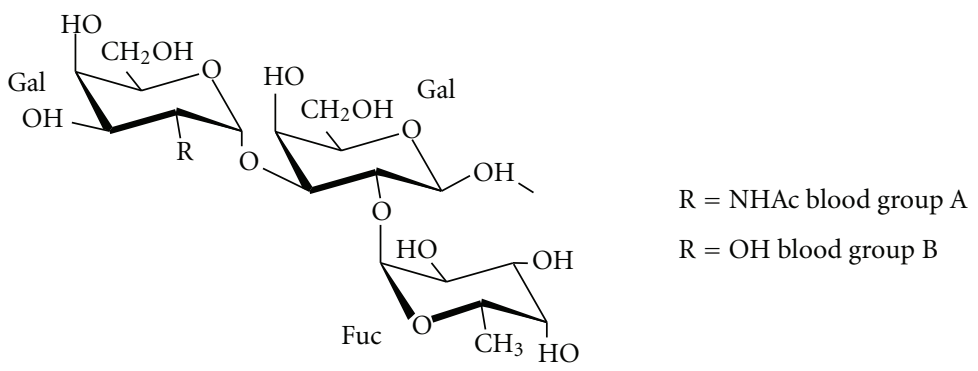

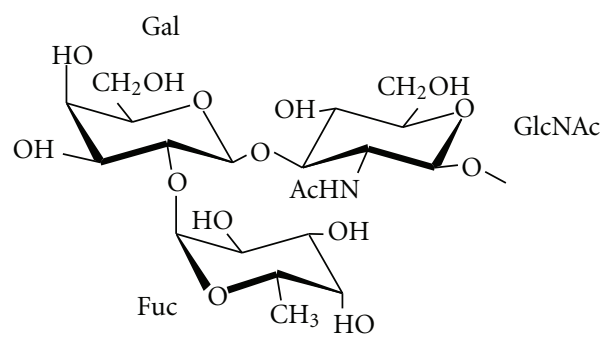

H type 1

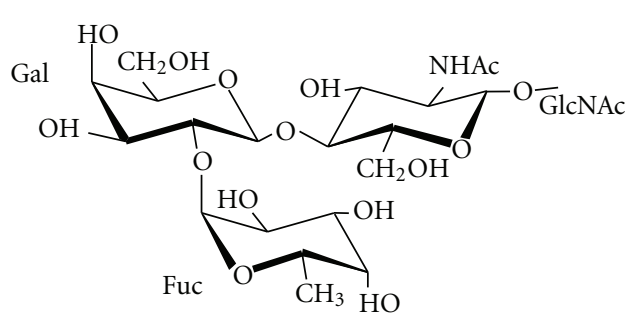

H type 2

Lewis antigens
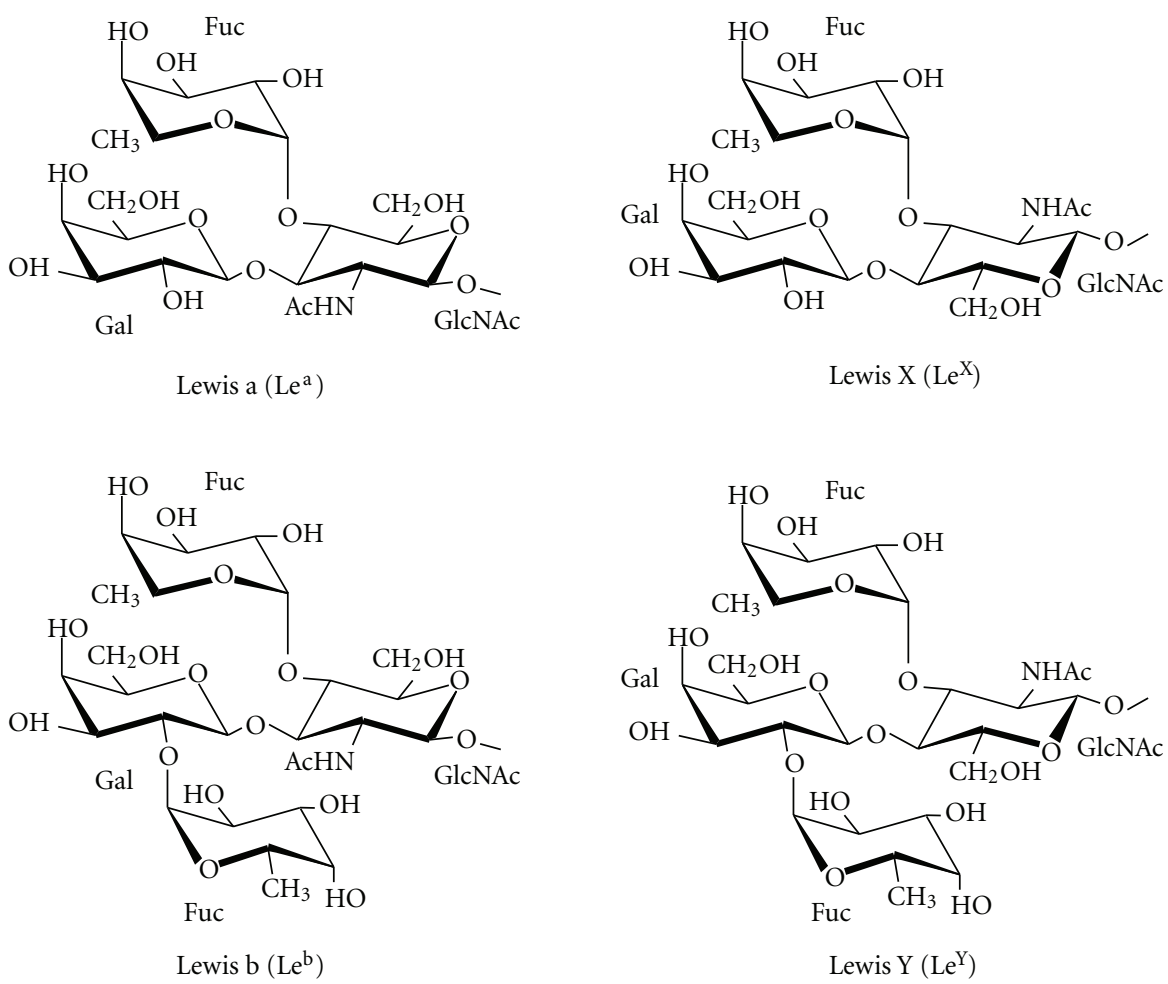

Lewis b $\left(\mathrm{Le}^{\mathrm{b}}\right)$

(a)

Figure 1: Continued. 

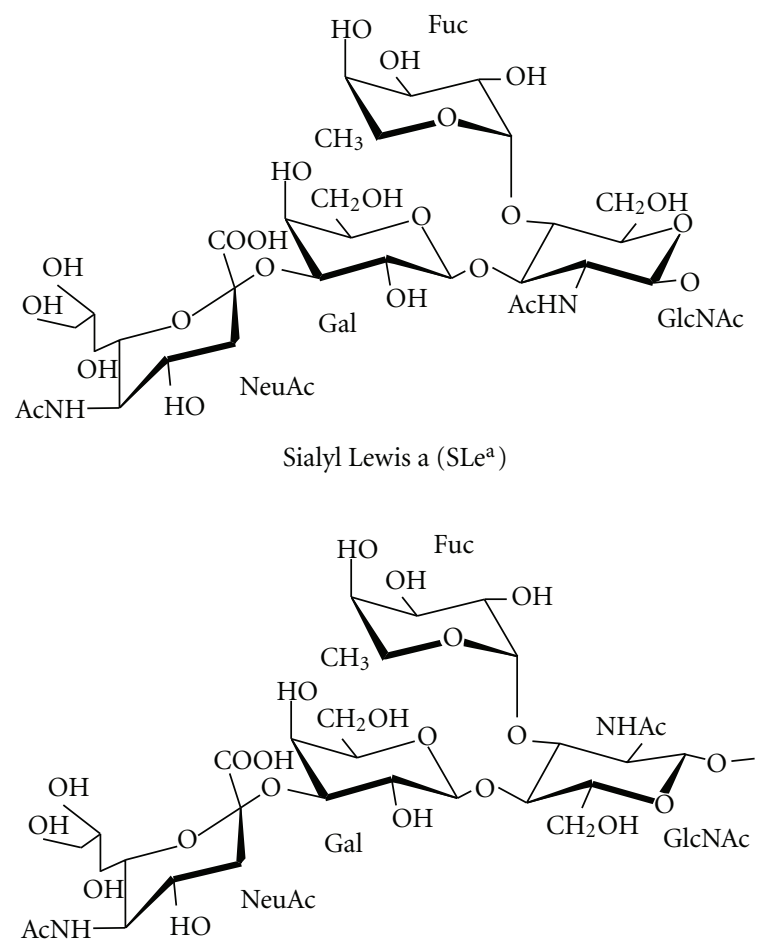

Sialyl Lewis X (SLe $\left.{ }^{\mathrm{X}}\right)$

(b)

FIGURE 1: Schematic representation of histo-blood group oligosaccharides.

The objective of this study was to explore the conformational behaviour of those oligosaccharides in explicit water model at $300 \mathrm{~K}$ for $10 \mathrm{~ns}$ using the GLYCAM 06 force field.

\section{Theoretical Approach}

The atomic labelling and the torsion angles of interest are given in Figure 2. The torsion angles $\varphi, \psi$ are defined $\varphi=\vartheta$ $\left(05-\mathrm{Cl}-0^{\prime} 2-\mathrm{C}^{\prime} 2\right), \psi=\vartheta\left(\mathrm{Cl}-0^{\prime} 2-\mathrm{C}^{\prime} 2-\mathrm{C}^{\prime} 3\right)$, and $\omega=\vartheta(\mathrm{O} 5-$ C5-C6-O6). The conformations with specific torsion angles $\omega$ are referred to as gauche-trans (gt; $\omega=60^{\circ}$ ), gauchegauche (gg; $\left.\omega=-60^{\circ}\right)$ and trans-gauche $\left(\operatorname{tg} ; \omega=180^{\circ}\right)$.

The MD simulations were carried out using AMBER10 [9] at a temperature of $300 \mathrm{~K}$. This temperature was chosen because our primary objective was to study the dynamics of the oligosaccharides at physiologically relevant conditions. The starting Lewis $\mathrm{X}$ pentasaccharide and trisaccharide monomer coordinates and parameters were constructed with the "Glycam Biomolecule Builder" available online from the website of Woods group [10] (see Schemes 1 and 2).

Since these coordinates are not optimized, a first minimization by molecular mechanics (1,000 steps of steepest descent followed by 1,000 steps of conjugate gradient minimization with a gradient tolerance of $0.05 \mathrm{kcal} \mathrm{mol}^{-1}$ ) was made with AMBER package version 10 [9]. Force field GLYCAM 06 was used for oligosaccharides (it used to simulate the interatomic interactions responsible for oligosaccharide

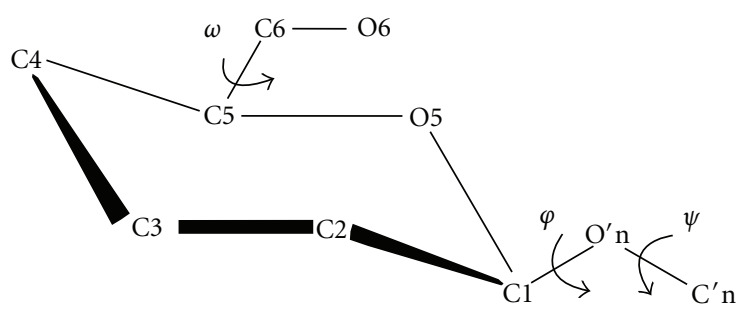

FIgURE 2: Atomic labeling and torsion angles of interest.

and glycoprotein dynamics and is currently suitable for all biologically relevant $\mathrm{N}$ - and O-linkages in oligo- and polysaccharides and glycoproteins [11]). The simulations were carried out using an explicit solvent environment with AMBER package version 10 . The solvated system for the oligosaccharides molecules was prepared using an explicit water box of $8 \AA$ in the xleap module of AMBER10. The number of water molecules was 569 for the trisaccharide and 1072 for the pentasaccharide. All simulations were run with the SANDER module of AMBER with SHAKE algorithm [12] (tolerance $=0.0005 \AA$ ) to constrain covalent bonds involving hydrogens, using periodic boundary conditions, a 2 fs time step, a temperature coupling [13], a 8 Á cutoff was applied to the Lennard-Jones interaction, and constant pressure of $1 \mathrm{~atm}$. The nonbonded list was updated every 


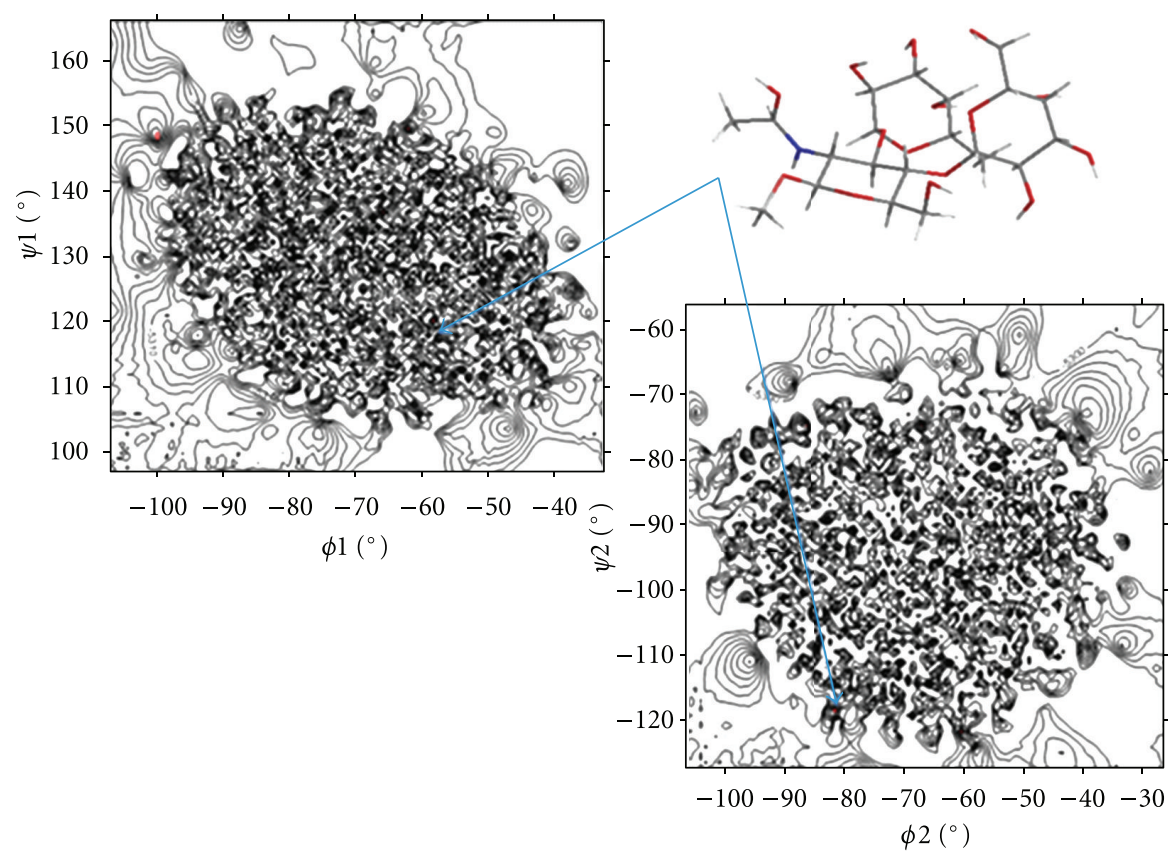

FIGURE 3: Relaxed conformational energy maps for the trisaccharide Lewis X calculated using the GLYCAM 06 force field.

10 steps. This preliminary study was aimed at finding the most energetically favorable structure which was found at 4856.9 ps for the trisaccharide and at $2411.8 \mathrm{ps}$ for the pentasaccharide. Those conformations were found with a "home-made" Perl script that merely checked all energies values, finding the lowest one and giving the associated structure [2].

The PTRAJ module of AMBER10 was used to analyze and process the trajectory and coordinate files from SANDER, where the analyses might include carrying out superimposition, clustering analysis of hydrogen bonds, calculating fluctuations in bonds, angles, or dihedrals, correlation functions, and so forth, and the root mean-square deviations (RMSDs).

Finally, isoenergy contour maps were generated with ORIGIN and SURFER 9 (Golden Software, Inc., Golden Co) [14]. The positions of the minima in these maps were subsequently calculated by minimizing the energy without restraints of those grid points indicating minima on the maps.

\section{Results}

The calculated adiabatic conformational energy surfaces $(\varphi$, $\psi$ ) for the tri- and pentasaccharide Lewis $\mathrm{X}$ are presented as potential energy contour maps in Figures 3 and 4, respectively. The contours are separated by $1 \mathrm{kcal} / \mathrm{mol}$ and range from 1 to $10 \mathrm{kcal} / \mathrm{mol}$. The energies are given relative to the lowest minimum. Geometries and relative potential energies of the predicted minima are listed in Tables 1 and 2 , and the lowest energy conformers for each compound are shown in Figures 3 and 4.
TABLe 1: Potential Energy, torsional angles for the conformers with low energies of the trisaccharide Lewis X.

\begin{tabular}{lccccc}
\hline & $\mathrm{PE}(\mathrm{kcal} / \mathrm{mol})$ & $\varphi_{1}\left(^{\circ}\right)$ & $\psi_{1}\left(^{\circ}\right)$ & $\varphi_{2}\left(^{\circ}\right)$ & $\psi_{2}\left(^{\circ}\right)$ \\
\hline Conformer 1 & -5446.95 & -61.84 & 124.7 & -61.54 & -104.33 \\
Conformer 2 & -5442.50 & -84.91 & 155.63 & -69.95 & -92.95 \\
Conformer 3 & -5440.08 & -80.60 & 139.25 & -55.46 & -98.51 \\
Conformer 4 & -5437.12 & -56.58 & 130.28 & -59.61 & -80.28 \\
\hline
\end{tabular}

3.1. System Root-Mean-Square Displacement. RMSD is an important parameter for describing the system stability. Figures 5 and 6 show the function curves between mass weighted RMSD fit and the time of the tri- and pentasaccharide Lewis $\mathrm{X}$ during dynamics simulation process, respectively.

3.2. Computation of Phi/Psi for Modeled Oligosaccharide. In the present study, structure prediction of oligosaccharides has been made through the torsion angles phi $(\phi) /$ psi $(\psi)$. The combination of $\phi$ and $\psi$ angles fully determine the conformation of an oligosaccharide. Figures 3 and 4 show the distribution of sterically allowed and energy minimized conformations in $\phi / \psi$ glycosidic space obtained from our explicit solvent MD simulations for $10 \mathrm{~ns}$ in the case of the tri- and pentasaccharide Lewis $\mathrm{X}$, respectively. These figures also show the best conformers (which have the low energies). These conformers and their corresponding $\phi / \psi$ angular values are reported in Tables 1 and 2 for the tri- and pentasaccharide Lewis $\mathrm{X}$, respectively. 


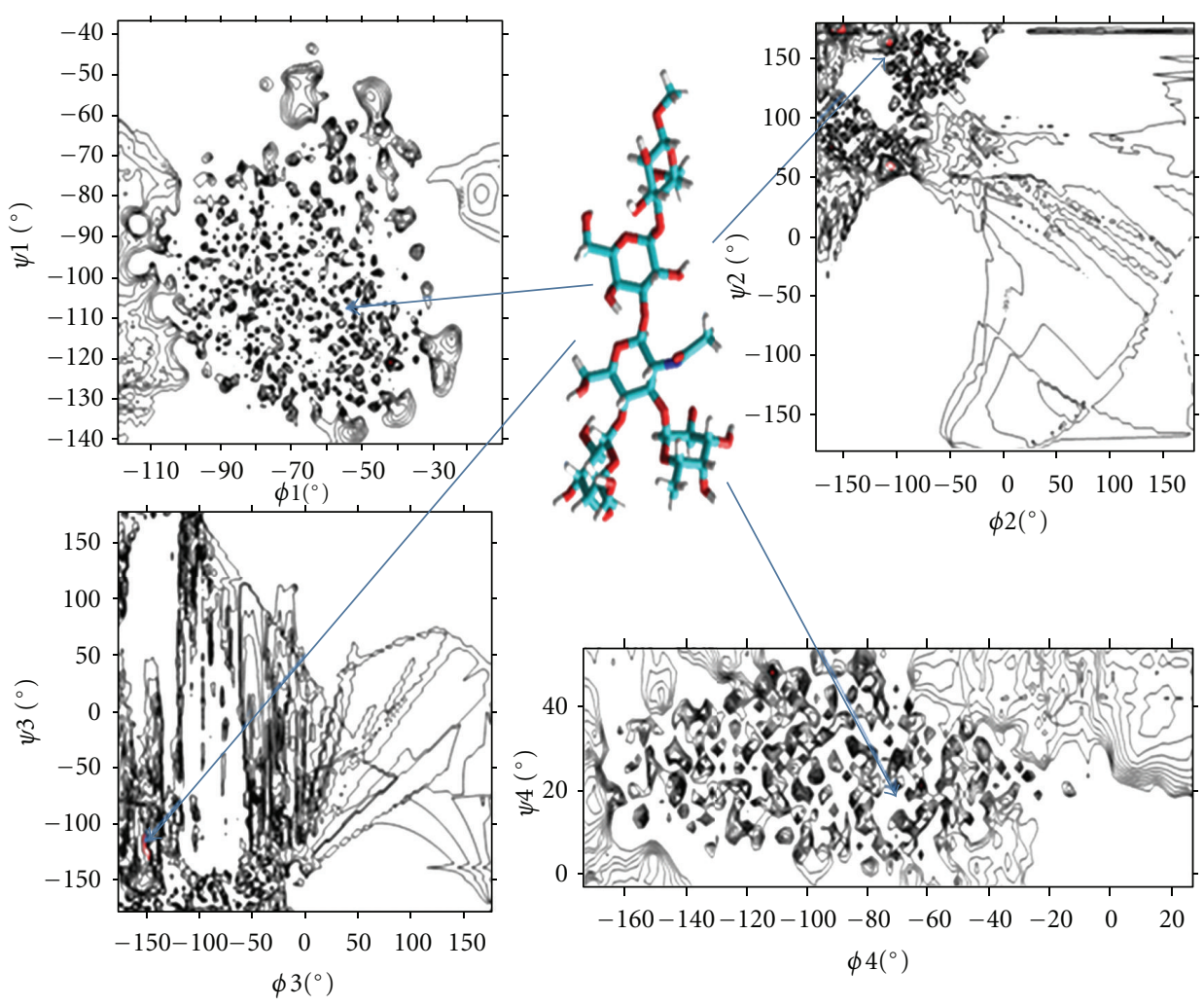

FIGURE 4: Relaxed conformational energy maps for the pentasaccharide Lewis X calculated using the GLYCAM 06 force field.

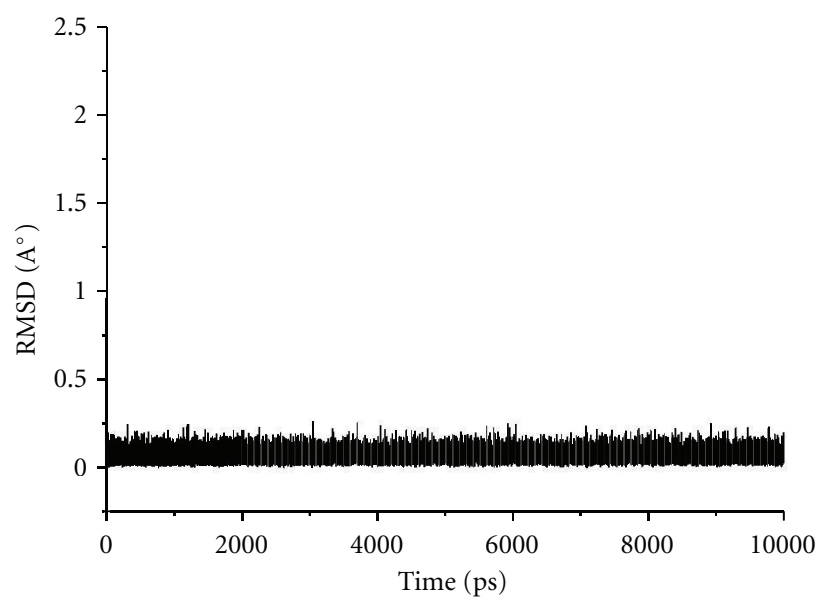

FIGURE 5: RMSD of the trisaccharide Lewis $\mathrm{X}$ as a function of time during MD, compared to the lowest-energy conformation.

TABle 2: Potential energy, torsional angles for the conformers with low energies of the pentasaccharide Lewis X.

\begin{tabular}{lccccccccc}
\hline & $\mathrm{PE}(\mathrm{kcal} / \mathrm{mol})$ & $\varphi_{1}\left({ }^{\circ}\right)$ & $\psi_{1}\left({ }^{\circ}\right)$ & $\varphi_{2}\left({ }^{\circ}\right)$ & $\psi_{2}\left({ }^{\circ}\right)$ & $\varphi_{3}\left({ }^{\circ}\right)$ & $\psi_{4}\left({ }^{\circ}\right)$ & $\varphi_{4}\left({ }^{\circ}\right)$ & $\psi_{4}\left({ }^{\circ}\right)$ \\
\hline Conformer 1 & -10191.15 & -78.30 & -97.88 & -124.4 & 64.97 & -108.27 & -173.37 & -57.54 & 15.18 \\
Conformer 2 & -10162.71 & -65.65 & -106.09 & -73.57 & 136.95 & -52.97 & -155.29 & -71.26 & 22.90 \\
Conformer 3 & -10162.25 & -56.49 & -112.26 & -78.58 & 144.67 & -55.95 & -157.92 & -69.85 & 23.71 \\
Conformer 4 & -10152.28 & -71.67 & -108.12 & -75.73 & 152.13 & -73.72 & -163.60 & -74.94 & 18.04 \\
\hline
\end{tabular}




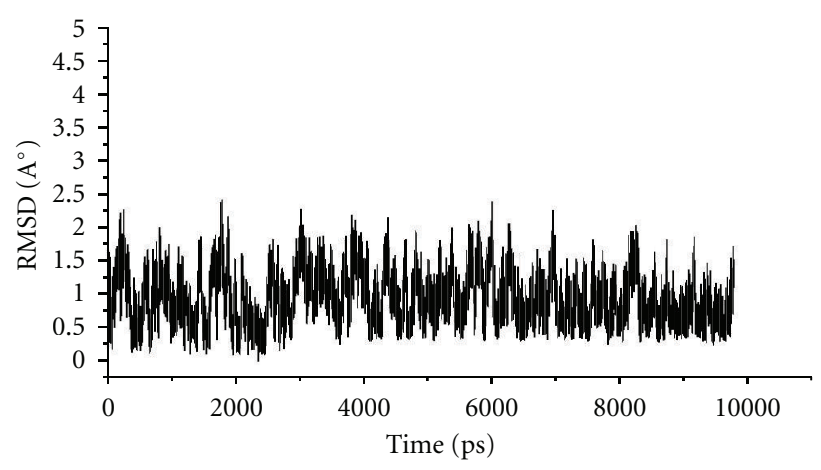

FIGURE 6: RMSD of the pentasaccharide Lewis $\mathrm{X}$ as a function of time during MD, compared to the lowest-energy conformation.

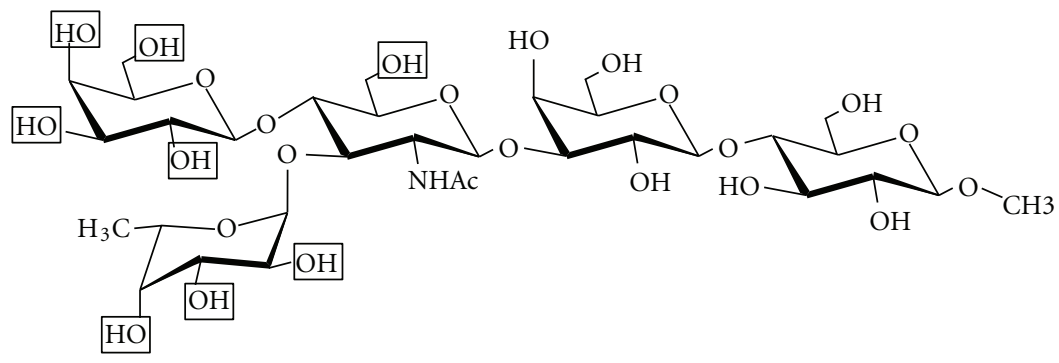

Lewis X pentasaccharide

Scheme 1: Lewis X trisaccharide.

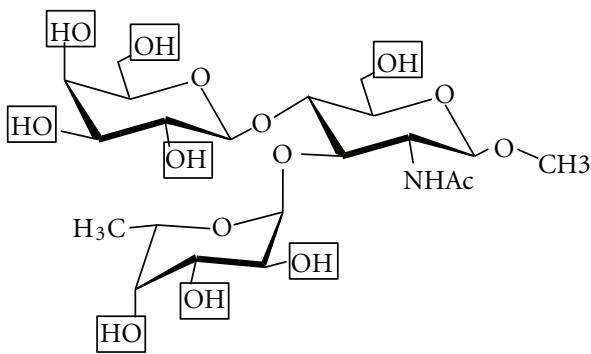

Lewis $\mathrm{X}$ trisaccharide

Scheme 2: Lewis X pentasaccharide.

\section{Discussion}

The monitoring of kinetic, global, and potential energies along the trajectory, as well as the pressure and temperature, indicate that the global periodic system is stable and does not present simulation artefacts. Kinetic energy increased slowly, whereas potential energy decreased gradually during the simulations. The total energy of a system to be simulated should be conserved, whereas the fluctuation of a temperature is caused by the interconvention of the kinetic and potential energy components [15].

The RMS variations as a function of time are displayed on Figures 5 and 6 for the tri- and penta-saccharide Lewis X respectively, and indicate that both systems are equilibrated after 500 ps. The visual examination of the two 10 ns trajectories shows that both oligosaccharides are stable. An RMSD analysis was carried out to quantify the structural differences. The RMSD between the PDB starting structure of the simulations (obtained from Glycam biomolecule builder), and the low-energy conformers structure considering only the heavy atoms is $0.03 \AA$ and $0.20 \AA$ for the tri- and penta-saccharide respectively. This shows that both oligosaccharides are stable.

During the simulation of those oligosaccharides, we notice that for the pentasaccharide the most stable conformer is obtained at 2411.8 ps and that for the trisaccharide was obtained at $4856.9 \mathrm{ps}$. This means that the pentasaccharide is less flexible than the trisaccharide due to the steric effect.

\section{Conclusion}

A complete understanding of the role of carbohydrates in biological systems is to a large extent dependent on the information available about the equilibrium mixture and about the preferred conformation of the carbohydrate molecules in solution. The conformational analysis offers a tool which can determine all possible conformations which influence the solution behavior of carbohydrates. This work represents a theoretical study of tow oligosaccharides tri- and pentasaccharide Lewis $\mathrm{X}$ using molecular dynamic simulations in explicit water with the AMBER10 program 
package. RMSD measures of the accuracy of carbohydrates around their average conformations play an important indicator of many biological processes such as macromolecular recognition and complex formations [16].

\section{Acknowledgments}

The authors are grateful to Dr. R. Borsali, Dr. K. Mazeau, Dr. A. Rivet, and Dr. A. Nurisso (CERMAV) France, and they thank particularly Mr. Guendouzi A for his help.

\section{References}

[1] A. Imberty and S. Perez, "Structure, conformation, and dynamics of bioactive oligosaccharides: theoretical approaches and experimental validations," Chemical Reviews, vol. 100, no. 12, pp. 4567-4588, 2000.

[2] Y. Luo, F. Barbault, C. Gourmala et al., "Cellular interaction through LewisX cluster: theoretical studies," Journal of Molecular Modeling, vol. 14, no. 10, pp. 901-910, 2008.

[3] E. A. Kabat, "Immunochemical studies on the carbohydrate moiety of water-soluble blood group A, B, H, Le ${ }^{\mathrm{a}}$, and $\mathrm{Le}^{\mathrm{b}}$ substances and their precursor I antigens," in Carbohydrates in Solution, H. Isbell, Ed., vol. 117, pp. 334-355, American Chemical Society, Washington, DC, USA, 1973.

[4] W. M. Watkins, "Biochemistry and genetics of the ABO, Lewis, and P blood group systems," in Advances in Human Genetics, H. Harris and K. Hirsch-Horn, Eds., vol. 10, pp. 1-136, Plenum Press, New York, NY, USA, 10th edition, 1980.

[5] S. I. Hakomori, "Antigen structure and genetic basis of histoblood groups A, B and O: their changes associated with human cancer," Biochimica et Biophysica Acta, vol. 1473, no. 1, pp. 247-266, 1999.

[6] F. Bizik and I. Tvaroska, "Conformational analysis of disaccharide fragments of blood group determinants in solution by molecular modelling," Chemical Papers, vol. 49, no. 4, pp. 202214, 1995.

[7] A. Imberty, E. Mikros, J. Koca, R. Mollicone, R. Oriol, and S. Perez, "Computer simulation of histo-blood group oligosaccharides: energy maps of all constituting disaccharides and potential energy surfaces of $14 \mathrm{ABH}$ and Lewis carbohydrate antigens," Glycoconjugate Journal, vol. 12, no. 3, pp. 331-349, 1995.

[8] T. Kozar and C.-W. von der Lieth, "Efficient modelling protocols for oligosaccharides: from vacuum to solvent," Glycoconjugate Journal, vol. 14, no. 8, pp. 925-933, 1997.

[9] D. Case, T. Darden, T. Cheatham et al., “AMBER,” University of California, CA, USA, 10th edition, 2006.

[10] R. J. Woods, R. A. Dwek, C. J. Edge, and B. FraserReid, "Glycam biomolecule builder," http://www.glycam.com/ CCRC/biombuilder/biomb_index.jsp.

[11] C. Gourmala, Y. Luo, F. Barbault et al., "Elucidation of the LewisX-LewisX carbohydrate interaction with molecular dynamics simulations: a glycosynapse model," Journal of Molecular Structure, vol. 821, no. 1-3, pp. 22-29, 2007.

[12] J. P. Ryckaert, G. Ciccotti, and H. J. C. Berendsen, "Numerical integration of the cartesian equations of motion of a system with constraints: molecular dynamics of $n$-alkanes," Journal of Computational Physics, vol. 23, no. 3, pp. 327-341, 1977.

[13] H. J. C. Berendsen, J. P. M. Postma, W. F. van Gunsteren, A. Dinola, and J. R. Haak, "Molecular dynamics with coupling to an external bath," The Journal of Chemical Physics, vol. 81, no. 8, article 3684, 7 pages, 1984.

[14] E. Y. Yoon, "A conformational study of linkage positions in oligosaccharides investigated by 2-D NMR spectroscopy and molecular modeling," Bulletin of the Korean Chemical Society, vol. 24, no. 3, pp. 339-344, 2003.

[15] J. A. McCammon and S. C. Harvey, Dynamics of Proteins and Nucleic Acids, Cambridge University Press, Cambridge, UK, 1987.

[16] E. B. Philip and W. Helge, Structural Boinformatics, 1st edition, 2003. 


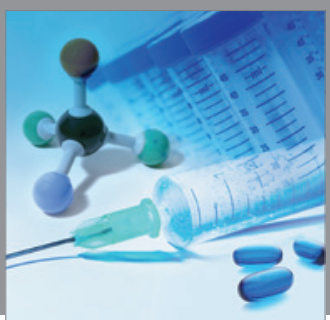

International Journal of

Medicinal Chemistry

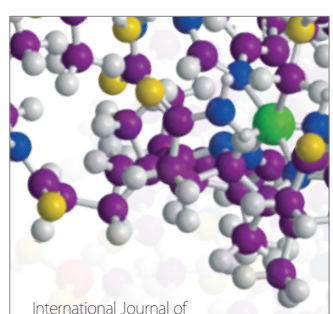

Carbohydrate Chemistry

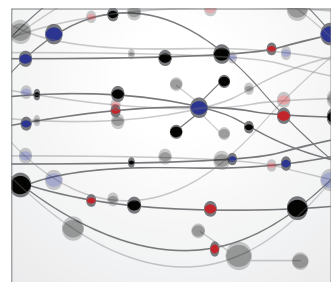

The Scientific World Journal
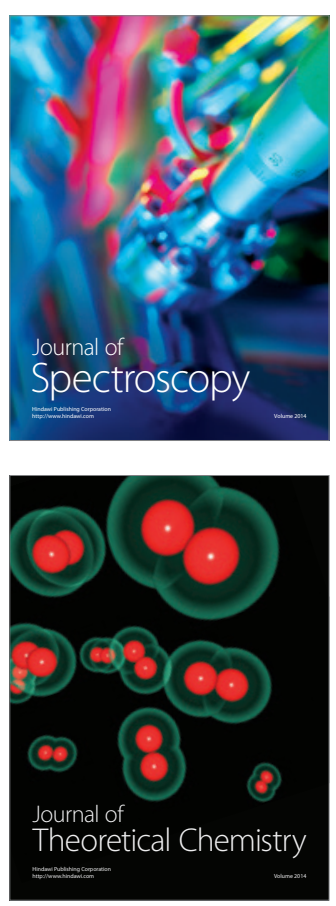
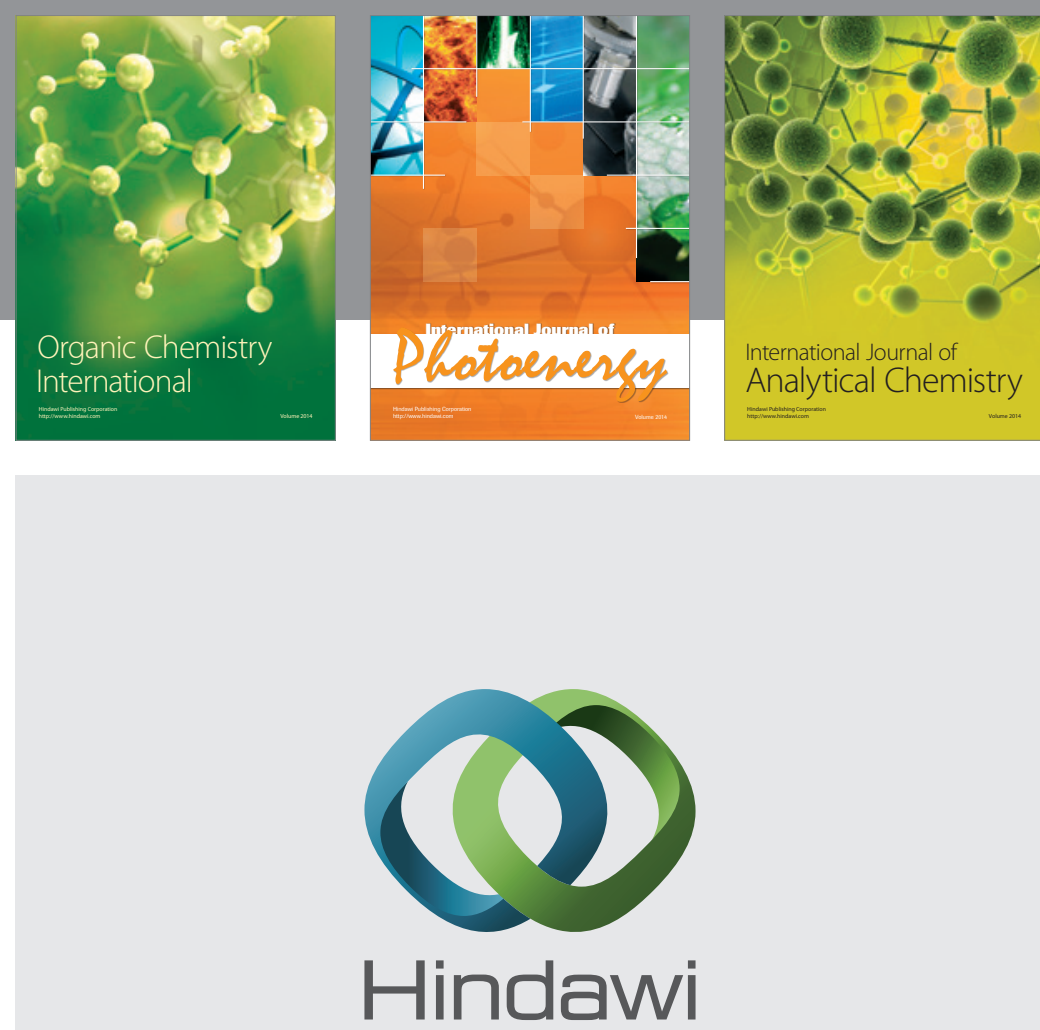

Submit your manuscripts at

http://www.hindawi.com
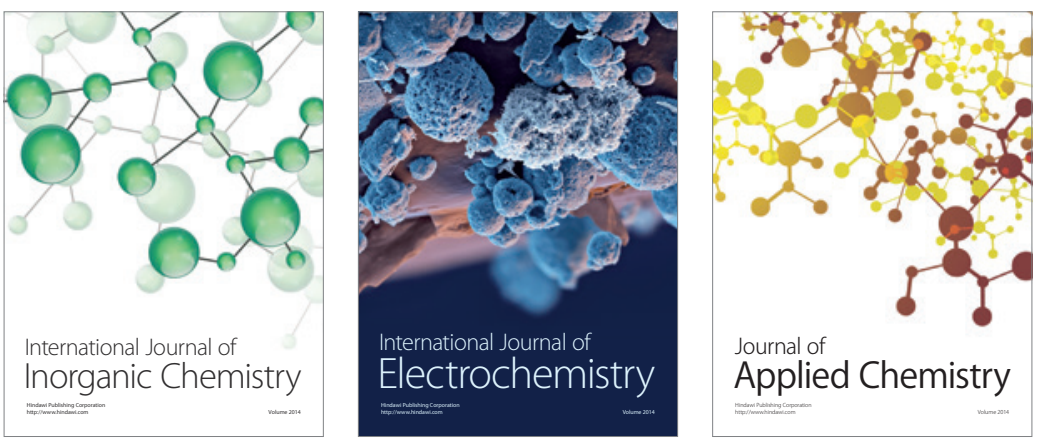

Journal of

Applied Chemistry
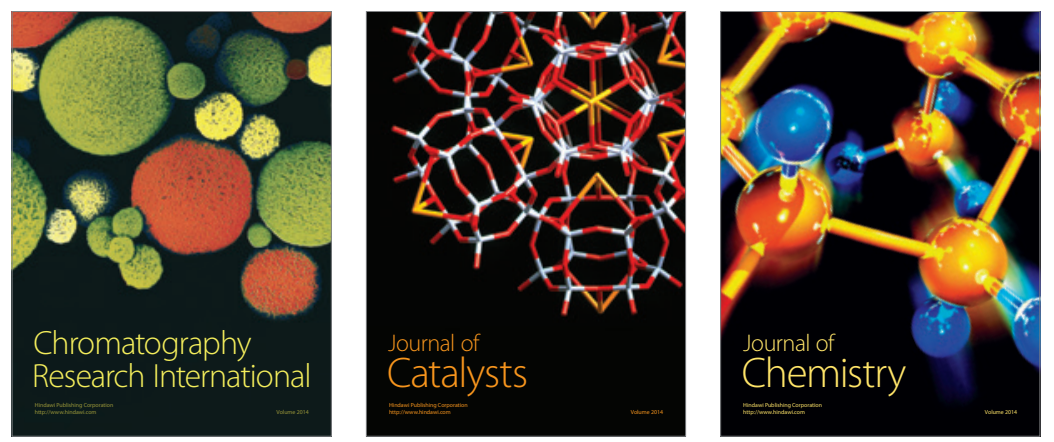
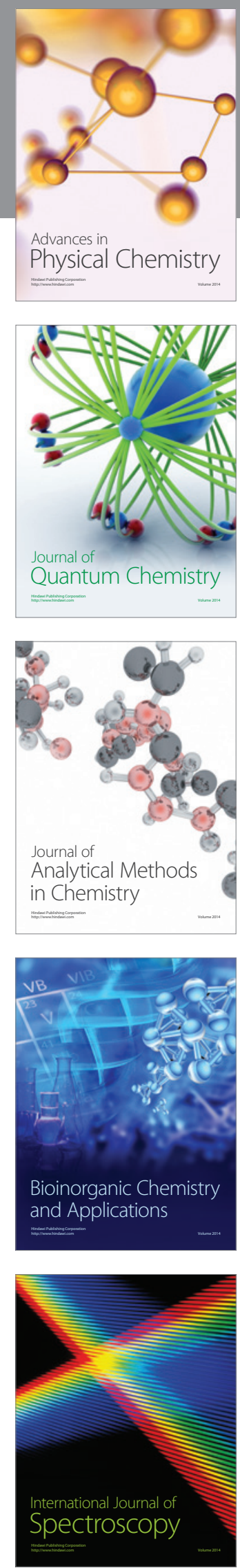